\title{
Substitutions of Two Amino Acids in the Nucleotide-Binding Site Domain of a Resistance Protein Enhance the Hypersensitive Response and Enlarge the PM3F Resistance Spectrum in Wheat
}

\author{
Daniel Stirnweis, Samira Désiré Milani, Tina Jordan, Beat Keller, and Susanne Brunner \\ Institute of Plant Biology, University of Zürich, Zollikerstrasse 107, CH-8008 Zürich, Switzerland
}

Submitted 2 October 2013. Accepted 6 December 2013.

\begin{abstract}
Proteins with nucleotide-binding site (NBS) and leucine-rich repeat (LRR) domains are major components of the plant immune system. They usually mediate resistance against a subgroup of races of a specific pathogen. For the allelic series of the wheat powdery mildew resistance gene $P m 3$, alleles with a broad and a narrow resistance spectrum have been described. Here, we show that a broad $P m 3$ spectrum range correlates with a fast and intense hypersensitive response (HR) in a Nicotiana transient-expression system and this activity can be attributed to two particular amino acids in the ARC2 subdomain of the NBS. The combined substitution of these amino acids in narrow-spectrum PM3 proteins enhances their capacity to induce an HR in Nicotiana benthamiana, and we demonstrate that these substitutions also enlarge the resistance spectrum of the $P m 3 f$ allele in wheat. Finally, using Bph14, we show that the region carrying the relevant amino acids also plays a role in the HR regulation of another coiled-coil NBS-LRR resistance protein. These results highlight the importance of an optimized NBS-'molecular switch' for the conversion of initial pathogen perception by the LRR into resistance-protein activation, and we describe a possible approach to extend the effectiveness of resistance genes via minimal targeted modifications in the NBS domain.
\end{abstract}

In addition to physical and chemical barriers, plants have a nonadaptive, cell-autonomous immune system to protect themselves against potentially pathogenic organisms and viruses. This immune system comprises two layers of resistance that both involve receptors for nonself molecules or activities (Jones and Dangl 2006). The first layer is based on cell-surface receptors with extracellular sensor domains that detect conserved molecular patterns associated with multiple classes of microbes or with cell damage. To establish virulence, host-adapted pathogens have evolved mechanisms to either evade recognition by those pattern recognition receptors, employ so-called effectors to suppress immune responses of the host, or both. The second

Corresponding author: B. Keller; E-mail: bkeller@botinst.uzh.ch

* The $e$-Xtra logo stands for "electronic extra" and indicates that eight supplementary figures and two supplementary tables are published online.

(C) 2014 The American Phytopathological Society layer of plant immunity is mediated by resistance $(\mathrm{R})$ proteins. They specifically recognize pathogen effectors and elicitors directly or indirectly via detection of an alteration of a guarded host protein. Accordingly, the $R$ gene-activated resistance is referred to as effector-triggered immunity and the recognized gene products of the pathogens are named avirulence (Avr) proteins (Dodds and Rathjen 2010).

During coevolution of host and pathogen populations, new variants of $R$ and $A v r$ genes rapidly evolve, leading to a large diversity or fast turnover at the respective genomic loci. Consequently, a particular $R$ gene usually only prevents disease instigated by a subset of pathogen races. $R$ genes have been extensively employed in crop breeding programs, due to the high level of resistance provided by most of them and the resulting ease in phenotypic selection. However, the drawback of their use, especially in modern agricultural cropping systems, is their rapid loss of effectiveness. They are overcome by newly emerging or spreading pathogen strains with mutated or lost $A v r$ genes. The majority of $R$ genes code for proteins with a central nucleotide-binding site (NBS) and a C-terminally linked leucine-rich repeat (LRR) domain (Marone et al. 2013). The two most prominent classes of NBS-LRR resistance proteins are defined by their N-terminus, either a toll-interleukin- 1 receptor (TIR) domain or a domain with a coiled-coil (CC) structure. The TIR and CC domains were shown to provide an interface for oligomerization (Bernoux et al. 2011b; Chang et al. 2013; Maekawa et al. 2011) or to interact with guardee and signaling proteins (Ade et al. 2007; Mackey et al. 2002; Sacco et al. 2007; Shen et al. 2007; Tameling and Baulcombe 2007). The LRR domain is often considered the major determinant of recognition specificity (Padmanabhan et al. 2009). It was shown, for example, for the resistance genes L5/L6 (Dodds et al. 2006) and Rppl (Krasileva et al. 2010), that their gene products interact directly with the corresponding avirulence proteins via the LRR domain in a gene-for-gene specific manner.

The central ATPase part of many R proteins, the NBS domain, can be further subdivided into three subdomains, a nucleotidebinding (NB) module and the ARC1 and ARC2 subdomains designated according to their presence in the human apoptotic protease activating factor 1 (APAF-1), R proteins, and the Caenorhabditis elegans death-4 (CED-4) protein. All three subdomains are important for the ATPase activity that enables the NBS domain to act as a 'molecular switch' (Takken et al. 2006) controlling transition of the $R$ protein between an ATPand ADP-bound state. The two states usually correspond to an 
active and inactive structural conformation, respectively. Current mechanistic models for NBS-LRR proteins predict that an initial detection of nonself molecules or non-self modified host proteins leads to small structural changes in the receptor. Those are subsequently amplified into major conformational changes that are accompanied by a nucleotide exchange (Rafiqi et al. 2009; Takken and Goverse 2012). The shift of the equilibrium to the activated form enables the resistance receptor to oligomerize or mobilize downstream signaling components or both (Bernoux et al. 2011a).

For the PM3 resistance protein, domain-swap experiments in a transient resistance assay have shown that blocks of 19 or 40 polymorphic amino acids in the NBS domain of the proteins PM3A or PM3B, respectively, contribute to a quantitatively higher resistance level against wheat powdery mildew (Blumeria graminis f. sp. tritici) (Brunner et al. 2010). Interestingly, these two alleles exhibit an extended resistance spectrum compared with $P m 3 f$ or $P m 3 c$ (Brunner et al. 2010). In a large set of tested B. graminis f. sp. tritici isolates, Pm3a mediated resistance against $454 \mathrm{~B}$. graminis f. sp. tritici isolates, including all 173 races that also displayed avirulence on $P m 3 f$, thus exhibiting an extended resistance spectrum of $P m 3 f$. A similar pattern was observed for the broad-spectrum $P m 3 b$ allele compared with the narrow-spectrum $P m 3 c$ allele.

A deeper understanding of the underlying mechanisms of such resistance-spectrum extensions can potentially be important for enhancing crop resistance with rationally designed resistance genes. To our knowledge, such approaches to artificially improve resistance genes have only been achieved, so far, by modifications in the LRR domain, once via random mutagenesis (Farnham and Baulcombe 2006), and once via intragenic pyramiding of polymorphisms from two alleles (Brunner et al. 2010).

In this study, we were able to show that the property of an extended $P m 3$ resistance spectrum correlates with the intensity of hypersensitive response (HR) induction in a transient expression system. Based on Nicotiana infiltrations, we identified two amino acid polymorphisms in the ARC2 domain of PM3A/B/S that explain the enhanced HR and applied this knowledge to extend the resistance of the narrow-spectrum $P m 3 f$ allele in wheat. The importance of the identified region in the fine tuning of $\mathrm{HR}$ is demonstrated in an additional $\mathrm{R}$ protein of the CCNBS-LRR class. The presented study suggests a possible approach for the optimization of plant resistance via minimal targeted gene modifications.

\section{RESULTS}

\section{An extended resistance spectrum correlates with an enhanced HR of $P m 3$ alleles in an autoactivated form.}

The two Pm3 alleles $P m 3 a$ and $P m 3 b$ exhibit an extended resistance spectrum in comparison with the $P m 3$ alleles $P m 3 f$ and $P m 3 c$, respectively (Brunner et al. 2010). Polymorphic sequence blocks in the NBS domain, unique to $P m 3 a$ and Pm3b (Fig. 1A) (Bhullar et al. 2010), were shown to contribute to the enhanced resistance. Since the NBS domain is known to modulate $\mathrm{R}$ protein activity, it was speculated that the ability of $P m 3 a$ and $P m 3 b$ to recognize additional isolates, as compared with $P m 3 f$ and $P m 3 c$ might be due to a more intense signaling activity and not due to different recognition specificities in the LRR domain of these alleles.

To investigate this further, we conducted Agrobacterium tumefaciens-mediated transient expression experiments in Nicotiana benthamiana. This agroinfiltration system was widely used previously to investigate $R$ gene responses (Bendahmane et al. 2000; Houterman et al. 2009; Ma et al. 2012; Tang et al.
1996; Van den Ackerveken et al. 1996; Van der Hoorn et al. 2000; van Ooijen et al. 2008b). Usually coexpression of the matching $A v r$ gene is employed to induce $\mathrm{R}$ protein activity, but in the absence of a cloned AvrPm3 gene, it was necessary to activate the PM3 proteins via an autoactivating mutation. Therefore, we introduced into Pm3a, Pm3b, Pm3c, and Pm3f an aspartate-to-valine-substitution in the MHD motif (IHD in PM3) that has been shown to render many NBS-LRR proteins autoactive (Bendahmane et al. 2002; van Ooijen et al. 2008b; Williams et al. 2011). Indeed, this mutation (D502V in PM3A/B and $\mathrm{D} 501 \mathrm{~V}$ in $\mathrm{PM} 3 \mathrm{C} / \mathrm{F}$ ) resulted in cell-death induction upon transient expression (Fig. 1B through E). This effect was not visible when nonmutated $P m 3$ genes were overexpressed in Nicotiana benthamiana (Fig. 1D and E). Hereafter, these MHD mutant variants are designated by a superscript HR (e.g., $\left.P m 3 a^{H R}\right)$, since the programmed cell-death response is reminiscent of the HR, a characteristic resistance reaction of plant cells against biotrophic pathogens. When different autoactive $P m 3^{H R}$ alleles were agroinfiltrated into Nicotiana benthami$a n a$, a striking difference in the timing and intensity of the HR was observed. Infiltration of alleles with an extended resistance spectrum, $P m 3 a^{H R}$ and $P m 3 b^{H R}$, resulted in a completely necrotic spot within $45 \mathrm{~h}$ postinfiltration (hpi), whereas the respective $P m 3^{H R}$ alleles with narrow resistance spectra triggered only a moderate $\left(P m 3 c^{H R}\right)$ or delayed $\left(P m 3 f^{H R}\right)$ HR (Fig. $1 \mathrm{~B}$ through E). Thus, we conclude that a narrow (Pm3f or $P m 3 c$ ) or a broad (Pm3a or $P m 3 b$ ) resistance spectrum correlates with a mild or slow or an intense and fast HR, respectively, of autoactivated $P m 3^{H R}$ alleles in the Nicotiana transient expression system. We will refer to $P m 3$ variants with a fast and intense HR after agroinfiltration as 'strong' alleles and to those with a slower or milder HR as 'weak' alleles.

\section{HR is modulated by the combination} of two amino acids in the ARC2 subdomain.

As the strong alleles $P m 3 a$ and $P m 3 b$ specifically share the same ARC2 sequence, we checked whether any amino acids in this subdomain are polymorphic to the consensus sequence PM3CS in any of the other known 15 functional PM3 proteins. Two polymorphic amino acids identical to the $P m 3 a / b$ haplotype were found in PM3S. Interestingly, the polymorphic proline 456 and histidine 458 residues are exclusively shared by PM3S and the strong PM3A and PM3B proteins, but all other Pm3 alleles encode for leucine 456 and tyrosine 458 (Bhullar et al. 2010). Additionally, the amino acids 456 and 458 are the only two polymorphic amino acids between PM3M and PM3S (Bhullar et al. 2009, 2010) (Fig. 1A; Supplementary Fig. S1). These two alleles were, therefore, used to initially test whether P456 and H458 have an influence on HR in the Nicotiana expression system.

Autoactivated versions of $P m 3 s$ and $P m 3 m$ were produced via the MHD mutation (D501V) and, indeed, $P m 3 s^{H R}$-infiltrated spots showed a completely collapsed plant tissue at 45 hpi that was not observed with $P m 3 m^{H R}$ (Fig. 1F). $P m 3 m^{H R_{-}}$ mediated HR developed more slowly but was often indistinguishable from $P m 3 s^{H R}$ at 7 days postinfiltration (dpi) (Fig. 1G). We also introduced P456 and Y458 in Pm3c ${ }^{H R}$. The $\mathrm{PM} 3 \mathrm{C}$ protein does not share a polymorphic sequence block in the spacer and first LRR with the PM3A, PM3B, and PM3S proteins that have been described above to exhibit a strong $\mathrm{HR}$ phenotype in Nicotiana (Fig. 1A). Infiltrations with the double-mutated $P m 3 c^{H R} L 456 P / Y 458 H$ led to entirely collapsed spots within 45 hpi (Fig. 1B). In contrast, $P m 3 c^{H R}$ elicited no HR within 45 hpi and only mild cell-death symptoms, even within 7 dpi (Fig. 1B and C). Based on this result we can conclude that the HR-enhancing effect of P456 and H458 is independent of those amino acids in the spacer and first LRR that 
are shared by the PM3A, PM3B, PM3M, and PM3S proteins (Fig. 1A).

As for $P m 3 m^{H R}$ and $P m 3 c^{H R}$, the double substitution L456P/ Y458H also intensified the HR of $P m 3 f^{H R}$ (Fig. 1D and E). Remarkably, the Pm3f_L456P/Y458H construct without the MHD mutation did not show any signs of cell-death induction, even at 7 dpi (Fig. 1E). This shows that it is possible to modify
PM3F by the two amino acid changes to exhibit a faster and more intense HR but without rendering the protein autoactive.

To test whether a single amino acid substitution is sufficient for enhancing the HR, we performed infiltrations with L456P or $\mathrm{Y} 458 \mathrm{H}$ variants of $P m 3 c^{H R}$ and $P m 3 m^{H R}$. The effect of these single substitutions on $P m 3 c^{H R}$ appears negligible (Fig. 1B and C). For the $P m 3 m^{H R} \_L 456 P$ and $\_Y 458 H$ variants, a slightly
A

PM3CS CC

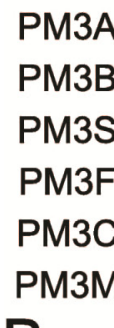

B

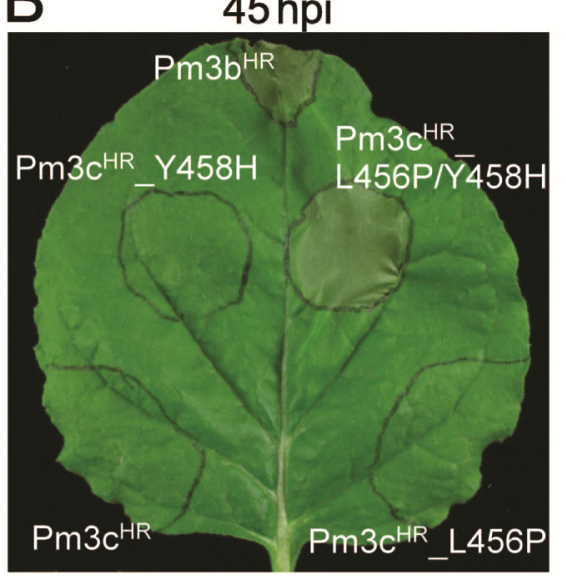

C

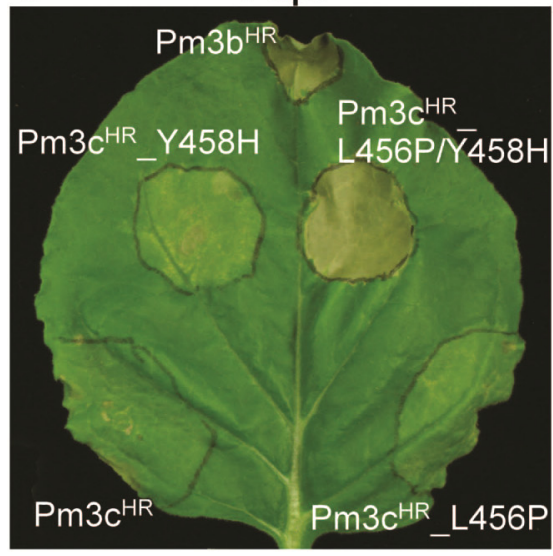

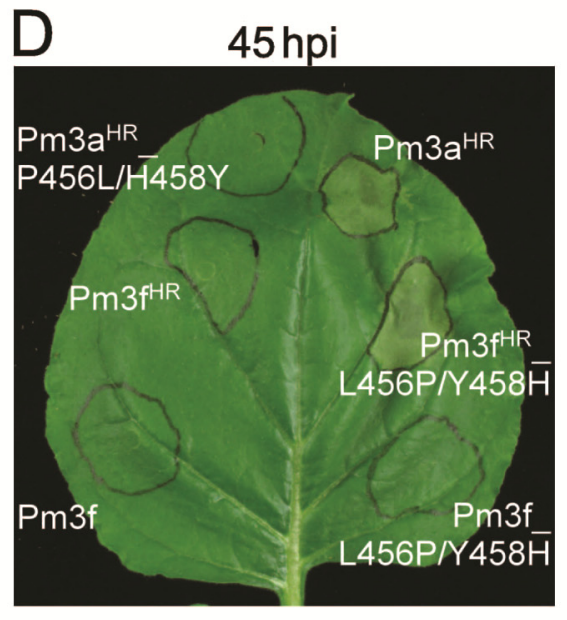

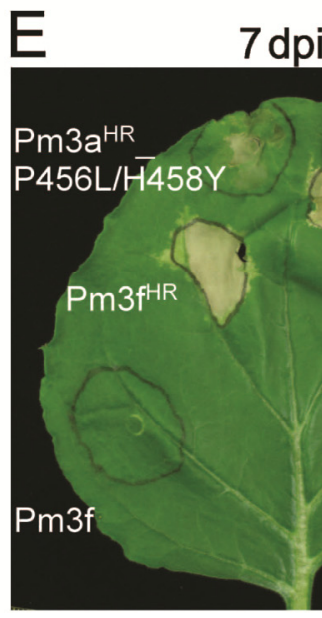

\section{HR induction after $P m 3^{H R}$ agroinfiltration}

strong

strong

strong

weak

weak

weak
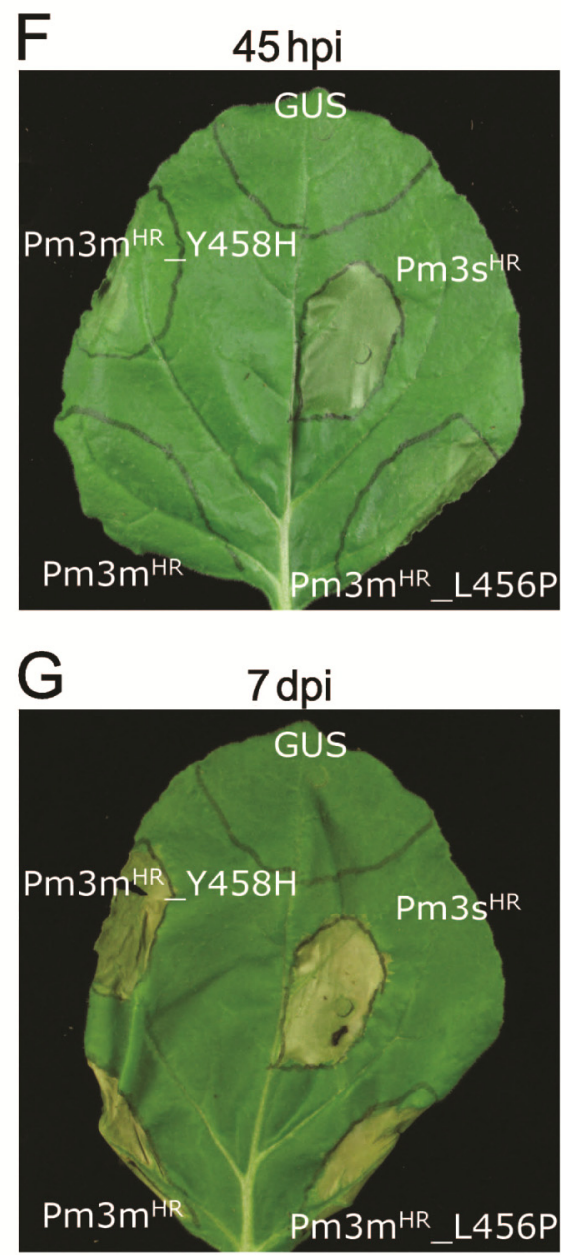

Fig. 1. $\mathrm{PM} 3^{\mathrm{HR}}$ proteins autoactivated by D-to-V mutations in the MHD motif differ in their ability to induce a hypersensitive response (HR) in a Nicotiana transient expression system. A, Schematic representations of the wild-type PM3 proteins used in this study. The top row shows the PM3 domain structure with the coiled-coil (CC) (blue), nuceotide-binding (NB) (red), ARC1 (salmon), ARC2 (dark red), spacer (gray), and leucine-rich repeat (LRR) (green) (sub)domains. Vertical bars are colored according to the domain affiliation and indicate polymorphic amino acids in comparison with PM3CS, the consensus sequence of all known PM3 proteins (Yahiaoui et al. 2006). Different Pm3 expression constructs were delivered into N. benthamiana leaves via Agrobacterium tumefaciens infiltration. Strength of the resulting HR after $P m 3^{H R}$ infiltration is indicated. B and $\mathbf{C}$, Introduction of the L456P/Y458H double substitution renders the narrow-spectrum allele $P m 3 c^{H R}$ nearly as effective in HR induction as the broad-spectrum allele $P m 3 b^{H R}$. The respective single substitutions display only a minimally enhanced HR. D and E, Infiltrated spots with $P m 3 a^{H R}$ and double-mutated $P m 3 f^{H R} \_L 456 P / Y 458 H$ display extensive cell death at 45 h postinfiltration (hpi), whereas $P m 3 f^{H R}$-cell death symptoms develop more slowly, and $P m 3 a^{H R} \_P 456 L / H 458 Y$ symptoms are even less pronounced by 7 days postinfiltration (dpi). Without the autoactivating mutation in the MHD motif, L456P/Y458H substitutions in Pm3f do not cause HR symptoms within 7 dpi. F and G, Cell-death induction by $P m 3 s^{H R}$ (equal to $P m 3 m^{H R}{ }_{-} L 456 P / Y 458 H$ ) causes a complete tissue collapse in the infiltration spot within 45 hpi, whereas HR induction by $P m 3 m^{H R}$ and its single substitution variants is slower. The negative control $\beta$-glucuronidase (GUS, uidA) does not induce cell death. B to G, Pictures of infiltrated leaves were taken at 45 hpi and $7 \mathrm{dpi}$ and representative examples are shown. 
intensified HR could be observed at 45 hpi in comparison with $P m 3 m^{H R}$ (Fig. 1F). But the combination of both substitutions, as present in $P m 3 s^{H R}$ and $P m 3 c^{H R} L 456 P / Y 458 H$, led to an exceedingly stronger HR (Fig. 1B, C, F, and G).

To more sensitively detect possible differences within the $\mathrm{Pm} 3 \mathrm{~m} / \mathrm{Pm} 3 \mathrm{~s}$ or $\mathrm{Pm} 3 \mathrm{~b} / \mathrm{Pm} 3 \mathrm{c}$ infiltration sets in the very early phase of HR induction (17 to $30 \mathrm{hpi}$ ), we performed measurements of electrolyte efflux from leaf discs, a frequently used proxy for cell-death quantification (Baker et al. 1991; Gao et al. 2011; Mackey et al. 2002; Maekawa et al. 2011). Here, a significant increase, in comparison with the negative control ( $\beta$-glucuronidase [GUS]), could be measured 23 to 30 hpi only for $P m 3 s^{H R}$ but not for $P m 3 m^{H R}$ or its single-substitution versions (Fig. 2A). Similar to $P m 3 s^{H R}, P m 3 b^{H R}$ also showed a fast increase in electrolyte leakage. However, no measurable deviation of electrolyte leakage between $P m 3 c^{H R} \_L 456 P / Y 458 H$ and $P m 3 c^{H R}$ could be detected within the first $30 \mathrm{hpi}$ and also, consistently, not with the two single-mutant variants of $P m 3 c^{H R}$ (Fig. 2B). The strong HR mediated by $P m 3 c^{H R}$ $L 456 P / Y 458 H$, therefore, predominantly developed between 30 and 45 hpi. The results of the $P m 3 m$ and $P m 3 s$ variants again suggest that both amino acid substitutions are necessary for the enhanced HR.
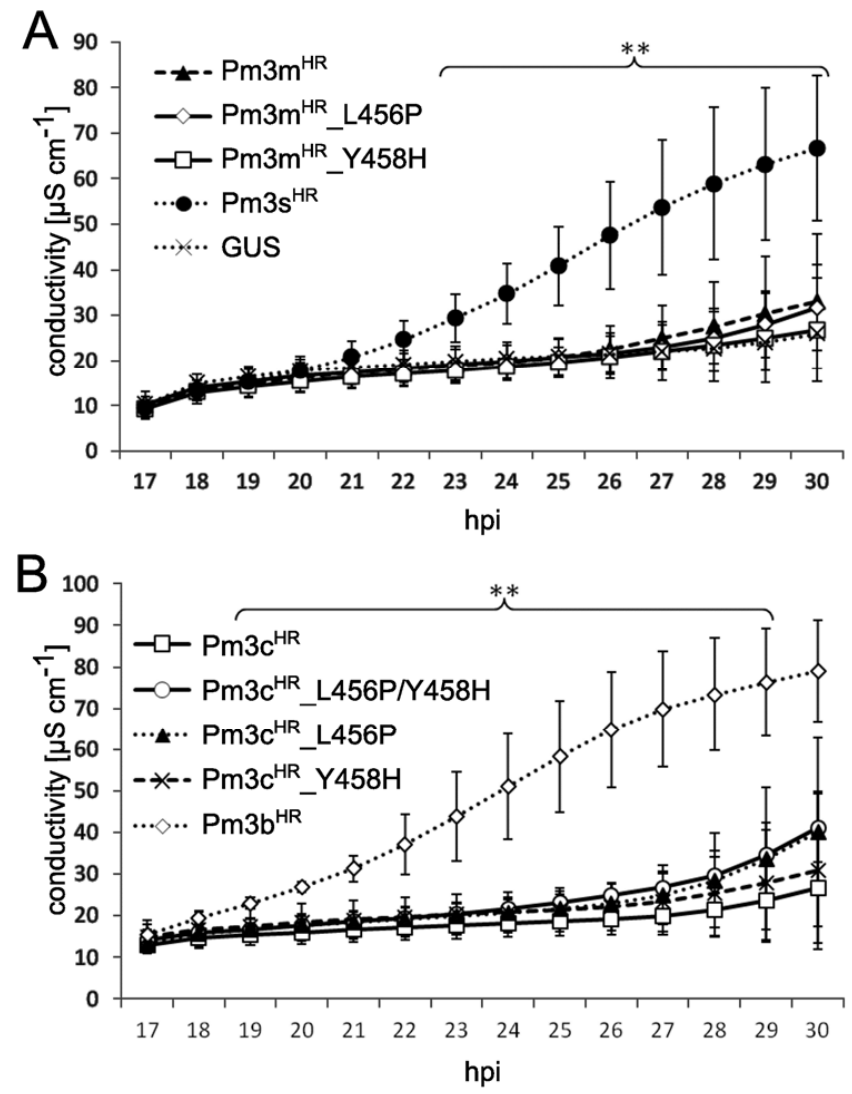

Fig. 2. Measurement of ion leakage in the early phase of hypersensitive response (HR) induction (17 to $30 \mathrm{~h}$ postinfiltration [hpi]) detects differences for the $P m 3 m / P m 3 s$ and $P m 3 b / P m 3 c$ infiltration sets. A, Within the first $30 \mathrm{hpi}$, increased electrolyte leakage from infiltrated leaf discs harvested 17 hpi can only be measured for $P m 3 s^{H R}$ in the $P m 3 m / P m 3 s$ infiltration set. $\beta$-glucuronidase (uidA)-infiltrated leaf discs represent a negative control for HR induction. B, Within the first $30 \mathrm{hpi}$, significantly increased electrolyte leakage can only be measured for $P m 3 b^{H R}$ in the $P m 3 b / P m 3 c$ infiltration set. Conductivity was measured in $1.5 \mathrm{ml}$ of $\mathrm{H}_{2} \mathrm{O}$ with one 7-mm diameter leaf disc and is illustrated as mean \pm standard deviation $(n=8)$. Relevant significant differences between $P m 3 s^{H R}$ (A) or $P m 3 b^{H R}$ (B) and all other samples in the respective infiltration set are reported $\left({ }^{* *} P<0.01\right.$, paired Student's $t$-test, same leaf as pairing criteria).
We conclude that the combined substitution of leucine 456 to proline and tyrosine 458 to histidine can convert weak into strong HR-inducing Pm3 alleles in the Nicotiana transient assay without rendering them autoactive.

\section{$P m 3 b$-mediated HR is also modulated}

by polymorphism outside the ARC2 subdomain.

The previous ion-efflux experiment with the $P m 3 b$ and $P m 3 c$ constructs showed that $P m 3 b^{H R}$-mediated, HR-related ion leakage started around $19 \mathrm{hpi}$, earlier, therefore, than the HR induced by the strong Pm3 $c^{H R} \_L 456 P / Y 458 H$. This suggests that additional HR-enhancing polymorphisms are present in $P m 3 b$ (Fig. 2B). The observation that the double mutated $P m 3 b^{H R} \_P 456 L / H 458 Y$ is not significantly compromised in its HR activity strongly supports this hypothesis (Fig. 3).

Interestingly, introduction of the same $\mathrm{P} 456 \mathrm{~L} / \mathrm{H} 458 \mathrm{Y}$ mutations in the strong $P m 3 a^{H R}$ allele almost completely abolished cell-death signaling and made $P m 3 a^{H R}{ }_{-} P 456 L / H 458 Y$ even less active than the respective weak allele $P m 3 f^{H R}$ (Fig. 1D and E). This highlights the importance of the two amino acids for PM3A-mediated signaling and allows the inference that the additional HR-enhancing polymorphisms in PM3B are located outside the ARC2, presumably in the NB-ARC1.

\section{The HR enhancing effect is not caused by modified protein stability and is independent of particular autoactivating mutations.}

To verify whether a higher $\mathrm{PM} 3^{\mathrm{HR}}$ protein abundance might be responsible for the more intense HR of the strong PM3 ${ }^{\mathrm{HR}}$ variants, we performed a Western blot analysis making use of a hemagglutinin (HA) epitope tag that was C-terminally fused to all PM3 proteins. We compared the PM3 ${ }^{\mathrm{HR}}$-protein levels in extracts from infiltrated spots from the same leaf, harvested shortly before the onset of cell death (15 hpi). Similar band intensities for the weak and the strong PM3 ${ }^{\mathrm{HR}}$ variants in the $\mathrm{Pm} 3 \mathrm{~m} / \mathrm{Pm} 3 \mathrm{~s}$ and $\mathrm{Pm} 3 \mathrm{~b} / \mathrm{Pm} 3 \mathrm{c}$ infiltration sets were found. This shows that the strong HR of the $P m 3 b^{H R}, P m 3 s^{H R}$, and $P m 3 c^{H R} \_456 P / Y 458 H$ alleles was not caused by higher protein abundance (Supplementary Fig. S2).

To test whether the enhancing effect of P456/H458 (proline 456/histidine 458) is specific for the MHD-mutant versions, we developed Pm3m and Pm3s genes mutated in the Walker B (Pm3_D284E) or RNBS-A motif (Pm3_S238F). They were designed based on described autoactive variants of the $R$ genes I-2 (Tameling et al. 2006) or Rps5 (Ade et al. 2007). While the D284E mutation did not lead to cell-death symptoms, the S238F

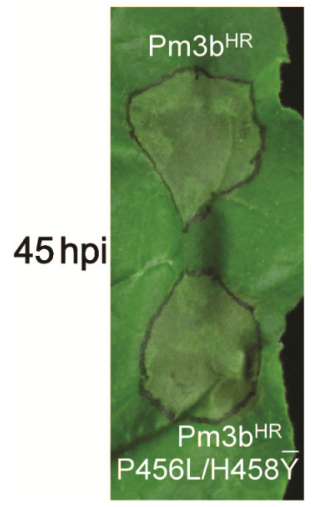

Fig. 3. Polymorphic amino acids distinct from $\mathrm{P} 456$ and $\mathrm{H} 458$ are also responsible for the fast and intense hypersensitive response (HR) mediated by $P m 3 b^{H R}$. Double-mutated $P m 3 b^{H R}{ }_{2} P 46 L / H 458 Y$ was not affected in HR induction compared with its wild-type version. A representative picture of an infiltrated leaf at $45 \mathrm{~h}$ postinfiltration is shown. 
substitution rendered $P m 3$ autoactive. The HR of $P m 3 s \_S 238 F$ was clearly more pronounced than the $P m 3 m \_S 238 F$ induced HR (Supplementary Fig. S3), showing that the enhancing effect is independent of a particular autoactivating mutation.

Modifications of two amino acids in the ARC2 domain result in an extended resistance spectrum of $P m 3 f$ in wheat.

We performed a transient resistance assay (Schweizer et al. 1999) in leaf epidermal cells of wheat, to explore whether the exchange of $\mathrm{L} 456 \mathrm{P} / \mathrm{Y} 458 \mathrm{H}$ may also result in an extended resistance spectrum of $P m 3 f_{-} L 456 P / Y 458 H$ in comparison with $P m 3 f$. Here, the constructs were biolistically delivered into epidermal cells of the susceptible wheat line 'Chancellor' and the leaves were subsequently infected with powdery mildew spores. The interaction of transformed cells with the fungus was quantified as a haustorium index (HI) that gives the percentage of attacked cells with a successfully established fungal haustorium (Fig. 4).

The $B$. graminis f. sp. tritici isolate 97028 differentiates the resistance reaction of $P m 3 a$ and $P m 3 f$ in seedling infection tests of wheat differential lines; it is avirulent on $P m 3 a$ and virulent on Pm3f. Whereas the HI of Pm $3 f$ for this isolate was $50 \% \pm 5 \%$, the construct Pm3f_L456P/Y458H $(16 \% \pm 5 \% \mathrm{HI}$; Student's $t$-test for comparison with $P m 3 f, P<0.001)$ showed a resistance level as high as the resistant $P m 3 a$ allele $(18 \% \pm$ $3 \% \mathrm{HI}$; Student's $t$-test for comparison with Pm3f_L456P/ $Y 458 H, P=0.579)$. We included in this assay the construct
$P m 3 f-a_{A R C}$, which encodes for a chimera of the CC-NBS domains of $P m 3 a$ and the spacer-LRR region of $P m 3 f$. It resembles a construct tested by Brunner and associates (2010) (same chimera but different plasmid vector and without the HA-epitope tag) that was employed to show an enhancing effect of the Pm3a-ARC2 subdomain on the Pm3f resistance. Since the HI of $P m 3 f-a_{A R C}(15 \% \pm 3 \% \mathrm{HI})$ for $B$. graminis $\mathrm{f}$. sp. tritici isolate 97028 was not significantly different from the HI of $P m 3 f \_L 456 P / Y 458 H$ (Student's $t$-test, $P=0.842$ ), we conclude that the other 17 polymorphic amino acids between PM3A and PM3F in the ARC2 domain do not further enhance the effectiveness of the modified Pm $3 f$ version. As a susceptible control, we also included Pm3CS throughout the assay. A comparison of the HI of Pm3f and Pm3CS for the isolate $97028-50 \% \pm 5 \%$ compared with $73 \% \pm 6 \%$, respectively (Student's $t$-test, $P<0.01$ )—indicates that $P m 3 f$ carries some residual recognition activity against the isolate 97028 , but this is not sufficient to trigger an efficient resistance response against this virulent race in the leaf segment assay (Fig. 4).

High HI values were obtained with all tested constructs in combination with the isolate AK3-11 (64 to $72 \% \mathrm{HI}$ ), which is virulent on Pm3a as well as Pm3f. This shows that none of the tested constructs activated unspecific resistance via autoactivation. As a further control, we used isolate 96224, which is avirulent on Pm3f and Pm3a. All constructs mediated high levels of resistance (4 to $12 \% \mathrm{HI}$ ), except for the susceptible control Pm3CS (68\% HI).

\section{Chancellor
Asosan $/ 8^{*} \mathrm{CC}(P m 3 a)$
M. Amber $/ 8^{*} \mathrm{CC}(P m 3 f)$}

Bgt 97028
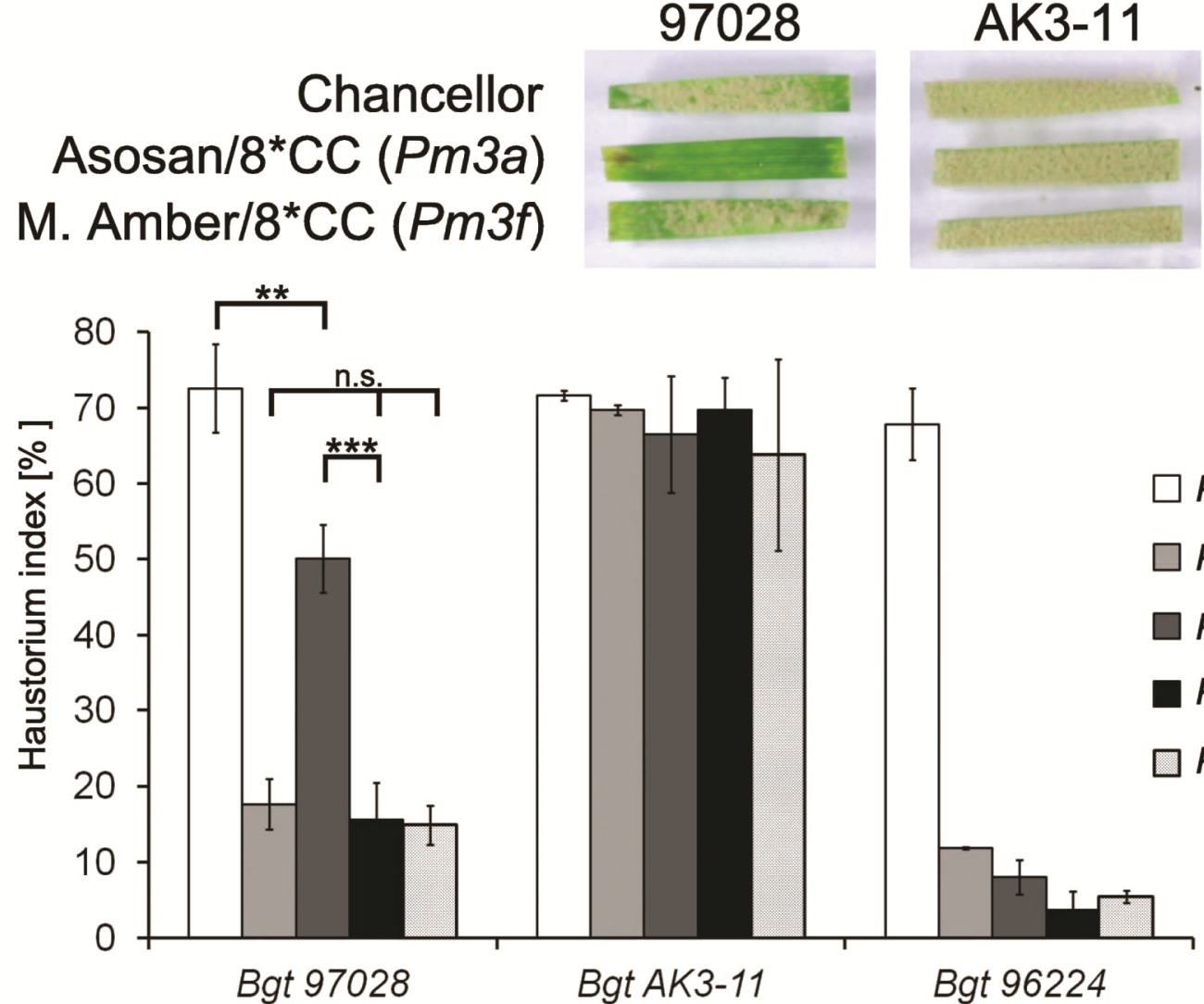

Bgt isolate
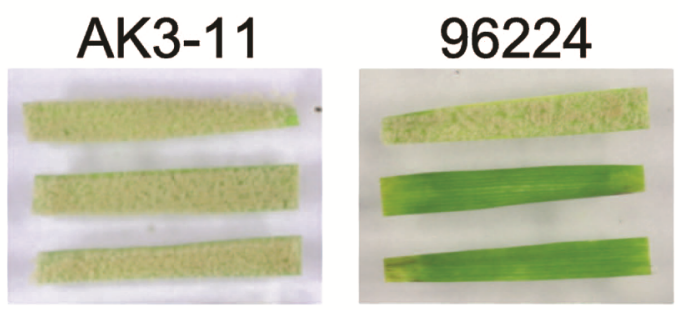

Fig. 4. Transient resistance assay in wheat reveals an enlarged powdery mildew resistance spectrum for the double-substituted $P m 3 f \_456 P / Y 458 H$ compared with $P m 3 f$. In the top panel, results of a seedling infection test with the susceptible cultivar Chancellor, which was used for the transient resistance assay, and with wheat differential lines for Pm3a and Pm3f are shown. The lower panel gives the results of the transient resistance experiments with the susceptible control Pm3CS, the wild-type alleles Pm3a and Pm3f, the double-substituted Pm3f_L456P/Y458H, and the Pm3f- $a_{A R C}$ chimera (coiled-coil and nucleotide-binding site of $P m 3 a$ and leucine-rich repeat domain of Pm3f). Haustorium index values (in percent) are reported as means ( \pm standard deviation) of three (Blumeria graminis f. sp. tritici $[$ Bgt] isolate 97028) or two (B. graminis f. sp. tritici isolates AK3-11 and 96224) independent experiments. Relevant (non-)significant differences are indicated (Student's $t$-test: n.s. $=$ nonsignificant, $* * P<0.01$, and $* * * P<0.001$ ). 
Overall, these results demonstrate that the substitution of the two relevant amino acids in the ARC2 domain converts Pm3f from a susceptible into a resistant allele with regard to the tested isolate 97028, thus expanding its resistance spectrum without inducing unspecific resistance mechanisms.
The $\mathbf{P 4 5 6 / H 4 5 8 ~ r e s i d u e s ~}$

of broad-spectrum $\mathrm{Pm} 3$ alleles represent

an optimal amino acid combination for a strong HR.

A nucleotide sequence alignment of Pm3 alleles revealed that the triplet coding for amino acid 456 differs between the

Table 1. Effects on the hypersensitive response (HR) observed in Nicotiana agroinfiltration assays for single amino acid substitutions of L456 or Y458 in autoactivated $P m 3 c^{H R}{ }_{-} Y 458 H$ or $P m 3 c^{H R}{ }_{2} L 56 P$, respectively

\begin{tabular}{|c|c|c|c|}
\hline Category & Effect on $H^{a}$ & $\mathrm{Pm} \mathrm{c}^{\mathrm{HR}} \_\mathrm{L} 456 \mathrm{x} / \mathrm{Y} 458 \mathrm{H}$ & Pm3c ${ }^{\mathrm{HR}}{ }_{-} \mathrm{L} 456 \mathrm{P} / \mathrm{Y} 458 \mathrm{x}$ \\
\hline \multirow[t]{2}{*}{$\bar{A}$} & $\begin{array}{l}\text { Strongly intensified HR: strong HR within } 45 \text { hpi; nearly as strong as for } \\
\qquad \text { Pm3 } \mathrm{c}^{\mathrm{HR}} \_ \text {L } 456 \mathrm{P} / \mathrm{Y} 458 \mathrm{H}\end{array}$ & Arg, Asp & Cys, Arg, Gln, Lys, Ser \\
\hline & Variable phenotypes between categories A and B & Ser, Gly, Gln, Asn, Lys & Pro, Ala, Thr, Trp, Asn \\
\hline B & $\begin{array}{l}\text { Weakly intensified HR: no strong HR within } 45 \text { hpi, but within } 7 \text { dpi } \\
\text { Variable phenotypes between categories B and C }\end{array}$ & $\begin{array}{l}\text { Thr, His, Tyr, Glu, Ile } \\
\text { Val, Ala, Cys }\end{array}$ & $\begin{array}{l}\text { Leu, Met, Phe } \\
\text { Gly, Ile }\end{array}$ \\
\hline $\mathrm{C}$ & $\begin{array}{c}\text { No change in HR: weak HR within } 7 \mathrm{dpi} \text {; indistinguishable from } \\
\text { Pm3 } \mathrm{c}^{\mathrm{HR}}{ }_{2} \text { L456P and Pm3 } \mathrm{c}^{\mathrm{HR}}{ }_{-} \mathrm{Y} 458 \mathrm{H}\end{array}$ & Phe, Met & Asp \\
\hline $\mathrm{D}$ & Loss of function: no HR within 7 dpi & $\operatorname{Trp}$ & Val \\
\hline
\end{tabular}

${ }^{\mathrm{a}}$ As compared with $\mathrm{Pm} 3 \mathrm{c}^{\mathrm{HR}} \_\mathrm{Y} 458 \mathrm{H}$ and $\mathrm{Pm} 3 \mathrm{c}^{\mathrm{HR}}{ }_{-} \mathrm{L} 456 \mathrm{P} ; \mathrm{hpi}=\mathrm{h}$ postinfiltration; dpi = days postinfiltration.
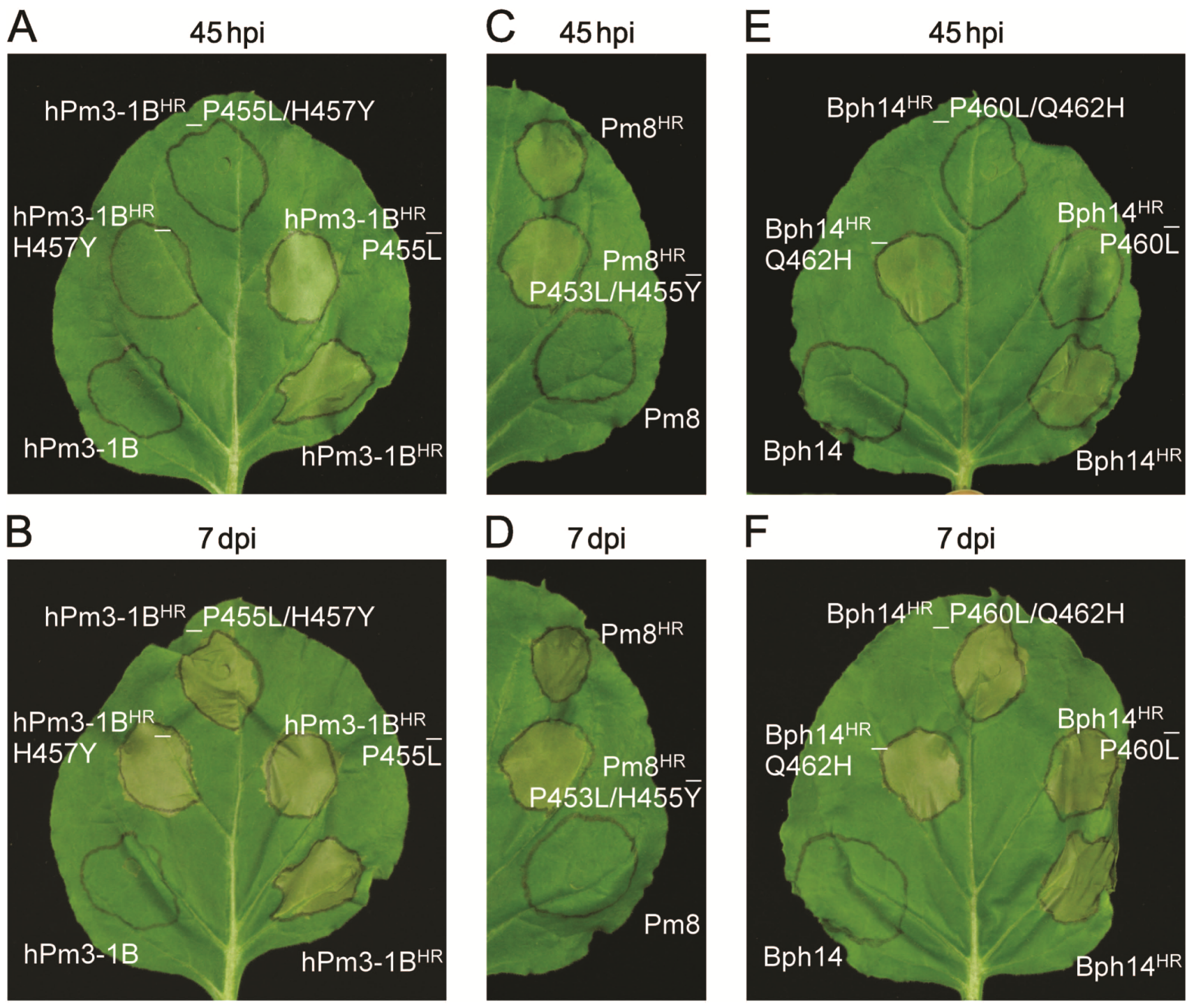

Fig. 5. Homologues of $P m 3$ that share the P456/H458 haplotype with strong $P m 3$ alleles ( $h P m 3-1 B$ and $P m 8)$ also induce a rapid and intense hypersensitive response (HR) in Nicotiana infiltrations and substitutions in the ARC2 loop of the coiled-coil nucletide-binding site leucine-rich repeat genes $h P m 3-1 B$ and Bph14 can modulate their HR activity. A to F, The contribution of the amino acids corresponding to P456 and H458 in strong Pm3 alleles to HR modulation is tested by single ( $h P m 3-1 B^{H R} \_P 455 L, h P m 3-1 B^{H R} \_H 457 Y, B p h 14^{H R}{ }_{2} P 460 L, B p h 14^{H R} \_$Q $\left.462 H\right)$ and double $\left(h P m 3-1 B^{H R} \_\right.$P455L/H457Y, Pm8 ${ }^{H R} \_P 453 L /$ $\left.H 455 Y, B p h 14^{H R} \_P 40 L / Q 462 \bar{H}\right)$ substitutions. HR development in Nicotiana benthamiana leaves agroinfiltrated with autoactivated variants of a Pm3 homolog from wheat chromosome 1B $\left(h P m 3-1 B^{H R}\right), P m 8\left(P m 8^{H R}\right)$, or Bph14 $\left(B p h 14^{H R}\right)(\mathrm{A}, \mathrm{C}, \mathrm{E}$, respectively) is shown at $45 \mathrm{~h}$ postinfiltration and $7 \mathrm{days}$ postinfiltration (B, D, F, respectively). Nonautoactivated $h P m 3-1 B, P m 8$, and $B p h 14$ do not induce cell death (B, D, F, respectively). 
strong alleles $P m 3 a / b$ and $P m 3 s$ and that polymorphisms in the close vicinity of this codon are not conserved between these alleles (Supplementary Fig. S4). This indicates that independent evolutionary events led to P456 (and presumably also to $\mathrm{H} 458$ ) in PM3A/B and in PM3S. Since the specific amino acid combination $\mathrm{P} 456 / \mathrm{H} 458$ evolved twice, we wanted to test what effects other amino acids cause in the respective positions. Therefore, we used the $P m 3 c^{H R}$-single-substitution constructs $\mathrm{Pm} 3 \mathrm{c}^{\mathrm{HR}} \_$L456P and $\mathrm{Pm} 3 \mathrm{c}^{\mathrm{HR}} \_\mathrm{Y} 458 \mathrm{H}$, which showed a very clear $\mathrm{HR}$ difference to the corresponding double-substituted gene (Fig. 1B and $\mathrm{C}$ ) and exchanged the second relevant amino acid (Y458 and L456, respectively) with any other amino acid. Nicotiana infiltrations with these constructs showed that many substitutions led to a stronger HR but the P456/H458 combination always caused the fastest HR. Whereas, for many other constructs, the HR scoring showed some variability, strongly intensified HR compared with the single-substituted $P m 3 c^{H R}$ was consistently observed for arginine or aspartate at position 456 and for cysteine, arginine, glutamine, lysine, or serine at position 458 (Table 1; Supplementary Figs. S5 and S6). Loss-of-function was observed with tryptophan at position 456 and valine or glutamate at position 458 , but in contrast to the constructs with W456 or V458, we did not detect PM3 $\mathrm{c}^{\mathrm{HR}}$ LL456P/Y458E protein, indicating that the $\mathrm{P} 456 / \mathrm{E} 458$ combination renders the protein unstable. For the two positions, physico-chemical properties of the different amino acid residues did not correlate with the effect on HR. On the one hand, these results show that the very moderate HR related to the L456/Y458 combination in narrow-spectrum $P m 3$ alleles is rather exceptional. On the other hand, the P456/H458 combination in strong Pm3 alleles seems to be an optimized amino acid combination regarding HR capacity.

\section{The ARC2 loop region modulates HR} of additional CC-NBS-LRR resistance genes.

According to a structural model of the NBS domain of PM3, the amino acids 456 and 458 are situated in an exposed loop (hereafter referred to as the ARC2 loop) connecting two $\alpha$ helices at the outer surface (Brunner et al. 2010) (Supplementary Fig. S7). An alignment of the PM3 protein sequence with numerous other plant NBS-LRR proteins shows that this loop is located C-terminally of the RNBS-D/RNBS-V motif (Meyers et al. 2003; Zhou et al. 2004) and is absent in TIR-NBS-LRR proteins. The loop is highly diverse among CC-NBS-LRR proteins but well conserved in hPM3-1B, a Pm3 homolog from wheat homologous chromosome 1B (Hurni et al. 2013), as well as in PM8, the Pm3 ortholog from rye (Secale cereale) (Hurni et al. 2013) (Supplementary Fig. S8). They both share the amino acid combination $\mathrm{P} 456 / \mathrm{H} 458$ with the $P m 3$ alleles with extended resistance spectra. When autoactive MHD mutants of PM8 and hPM3-1B were infiltrated in N. benthamiana, both also exhibited a very fast and intense HR (Fig. 5A and C). The double substitution $\mathrm{P} 455 \mathrm{~L} / \mathrm{H} 457 \mathrm{Y}$ in the ARC2 loop residues corresponding to amino acids 456 and 458 in PM3 markedly dampened the HR induction of hPM3-1B ${ }^{\mathrm{HR}}$ (Fig. 5A and B), as it was previously observed for PM3 $\mathrm{A}^{\mathrm{HR}}$ P456L/H458Y (Fig. 1D and E). Agroinfiltrations with the respective single-substitution variants showed that the H457Y exchange is sufficient to explain the reduced HR of hPM31B ${ }^{\mathrm{HR}}$ P455L/H457Y (Fig. 5A). The strong HR mediated by $\mathrm{hPM} 3-1 \mathrm{~B}^{\mathrm{HR}} \mathrm{P} 455 \mathrm{~L}$ is in contrast to $\mathrm{PM} 3 \mathrm{C}^{\mathrm{HR}} / \mathrm{PM} 3 \mathrm{M}^{\mathrm{HR}}$, in which the $\mathrm{L} 456 / \mathrm{H} 458$ combination results in a weak HR (Fig. $1 \mathrm{~B}, \mathrm{C}$, and F). These results demonstrate that, although the exact molecular details of HR modulation differ between PM3 and hPM3-1B, the ARC2 loop is also a key regulator of HR induction in hPM3-1B. No reduced HR could be observed after agroinfiltration of $P m 8^{H R}{ }^{P} P 456 L / H 458 Y$ compared with
$P m 8^{H R}$ (Fig. 5C and D). As suggested above for $\mathrm{PM} 3 \mathrm{~B}^{\mathrm{HR}}$ $\mathrm{P} 456 \mathrm{~L} / \mathrm{H} 458 \mathrm{Y}$, additional HR-enhancing polymorphic amino acids might be present in PM8.

Apart from PM8 and hPM3-1B, the sequence most closely related to the ARC2 loop of the PM3 proteins is present in Bph14, a CC-NBS-LRR protein conferring resistance against brown planthopper in rice (Du et al. 2009). A mutation of the MHD motif (D508V) autoactivates Bph14 ${ }^{H R}$, leading to a strong HR after infiltration in $N$. benthamiana. This HR activity could not be further enhanced by a substitution of glutamine 462 to histidine (Q462H; Fig. 5E and F), which corresponds to the weak-tostrong exchange $\mathrm{Y} 458 \mathrm{H}$ in PM3. This is consistent with the observation that glutamine at position 458 in the $\mathrm{Pm} 3 \mathrm{c}^{\mathrm{HR}}$ L456P/Y458Q construct also causes a strong HR (Table 1). However, when proline 460, corresponding to proline 456 in strong PM3, was replaced by leucine $(\mathrm{P} 460 \mathrm{~L})$, the occurrence of cell death induced by Bph14 ${ }^{\mathrm{HR}} \_$P460L was clearly delayed compared with Bph14 ${ }^{\mathrm{HR}}$, and consistently, the Bph14 ${ }^{\mathrm{HR}}$ P $460 \mathrm{~L} /$ Q462H construct also displayed a delayed HR (Fig. 5E and F). This demonstrates that this ARC2 loop region is also involved in the fine tuning of a distantly related CC-NBS-LRR protein.

\section{ARC2 loop substitutions that lead to a strong HR do not modify interdomain interactions between the CC-NBS and the LRR.}

Slootweg and associates (2013) demonstrated that, for Rxl/ Gpa2, particular amino acid exchanges in the ARC2 loop region

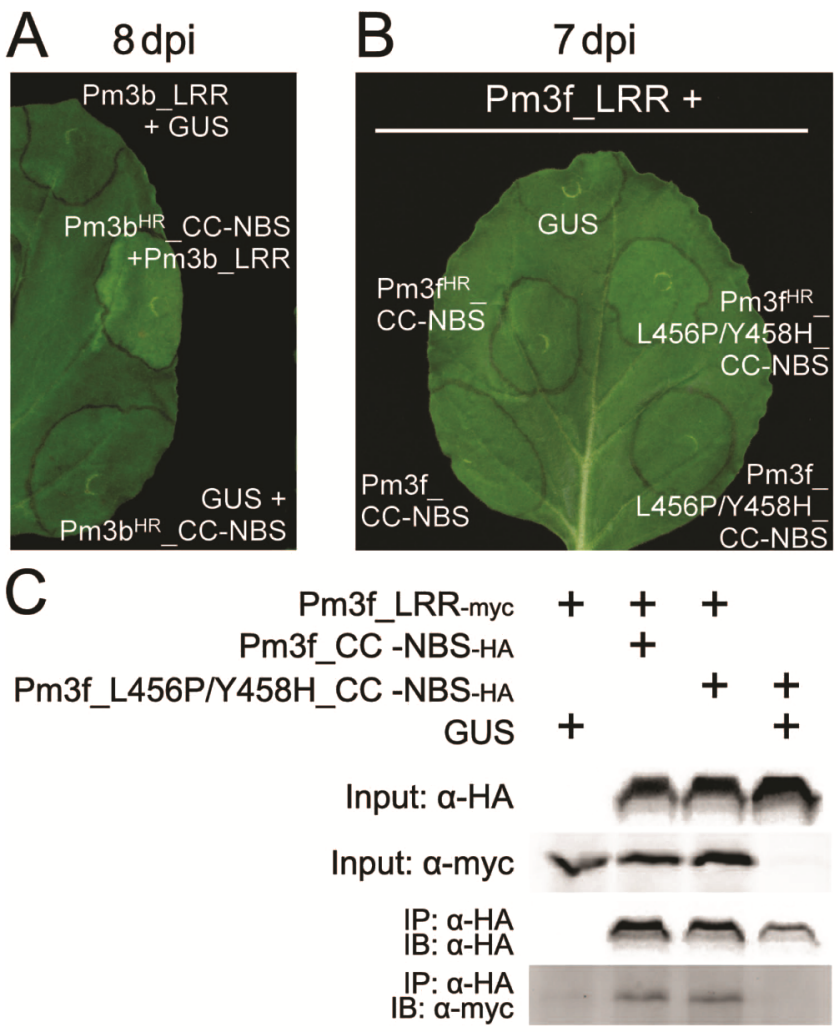

Fig. 6. Coimmunoprecipitation experiment reveals no modification of the PM3 coiled-coil nucleotide-binding site (CC-NBS) to leucine-rich repeat (LRR) domain interaction by the hypersensitive response (HR)-enhancing L456P/Y458H substitutions. A, Representative weak HR symptoms in Nicotiana leaves at 8 days after coinfiltation of PM3B CC-NBS and LRR fragments. B, Agroinfiltrations in Nicotiana benthamiana with the respective PM3F and PM3F_L456P/Y458H fragments are shown at 7 days postinfiltration. $\mathbf{C}$, Coimmunoprecipitation of c-myc-tagged LRR with hemagglutinin (HA)-tagged CC-NBS fragments of PM3F. Immune blots (IB) before (two upper panels) and after (two lower panels) immunoprecipitation (IP) with anti-HA-coupled agarose beads are shown. 
lead to a loss of HR activation in trans between the Gpa2 CCNBS and an autoactivating Rx1 LRR, most likely due to a reduction of the binding between the Gpa2 CC-NBS and the matching LRR fragment. This suggests that a stronger activation correlates with a more efficient binding of the ARC2 loop to the LRR.

To test whether the L456P/Y458H substitutions modify interdomain interactions of PM3, we split the PM3 protein into CC-NBS (PM3B:aa 1-524, PM3F:aa 1-523) and LRR parts (PM3B:aa 525-1415, PM3F:aa 524-1414). To test for in trans functionality of these fragments, we combined the CC-NBS carrying the D501V- or D502V-MHD mutation with the respective LRR in agroinfiltrations of Nicotiana benthamiana No macroscopic signs of HR were visible for the split PM3F, while a moderate HR was induced within 8 dpi by the split PM3B (Fig. 6A and B). Thus, the HR was severely reduced compared with the full-length $\mathrm{PM}_{3} \mathrm{~B}^{\mathrm{HR}}$ (Fig. $1 \mathrm{~B}$ and $\mathrm{C}$ ). To our knowledge, the in trans HR with corresponding fragments from Rx1 was not reported to be impaired compared with the full-length equivalent (Moffett et al. 2002). However, the weak HR induced by split PM3B and the lack of signs of transcomplementation of split PM3F may partially reflect observations with other CC-NBS-LRR that are not functional in trans with autoactivating mutations in the ARC2 subdomain (van Ooijen et al. 2008a). Nevertheless we could demonstrate that the chosen PM3B fragments are able to functionally interact to activate HR in trans. Therefore, we followed up the study on interdomain interactions of PM3.

Using the same CC-NBS and LRR fragments of PM3F, we performed a coimmunoprecipitation experiment to check for an altered CC-NBS-to-LRR affinity between the wild type and the L456P/Y458H-modified variant. Despite the lack of a transcomplementation phenotype, we were able to pull down the c-myc-tagged LRR domain with agarose bead-coupled antibodies against the HA-tagged CC-NBS domain, indicating that these protein fragments interact. However, no obvious difference in the amount of coprecipitated LRR could be detected when comparing the two CC-NBS variants (Fig. 6C). We infer that the HR-enhancing modifications in the ARC2 loop have no major impact on interdomain interactions between CC-NBS and LRR, at least in the transient Nicotiana system.

\section{DISCUSSION}

For many NBS-LRR resistance proteins, it was shown that effector or elicitor perception, the first step in determining resistance specificity, is mediated by the LRR domain. Using comparative sequence analysis of alleles (Yahiaoui et al. 2006) and domain-swap experiments (Brunner et al. 2010), this was also demonstrated for the $P m 3$ powdery mildew resistance gene. The translation of an initial detection into an efficient resistance response is attributed to the tightly regulated molecular switch function of the NBS domain, which consequently has to be considered as an important determinant of resistance specificity. In agreement with this model, it was shown that a polymorphic sequence block in the ARC2 subdomain of the NBS as present in the PM3A protein contributes to an expansion of the resistance spectrum in comparison with the PM3F protein (Brunner et al. 2010). In the study here, we were able to pinpoint two amino acids that completely explain this effect. Similar observations that the N-terminal domains modulate the resistance specificity of the LRR were made in other NBSLRR. The flax rust TIR-NBS-LRR resistance protein L6 differs from the L7 allele only in the TIR domain but has a broader resistance spectrum than $\mathrm{L} 7$, indicating that the resistance is modulated by the TIR domain (Dodds et al. 2006; Ellis et al. 1999; Luck et al. 2000). Three amino acid changes are sufficient to explain this difference (L2/L6 recombinant, Luck et al. 2000). Tomita and associates (2011) were able to show that the CC-NBS domains influence the recognition spectrum of the Tobamovirus resistance protein $\mathrm{L}^{3}$ from pepper. By combining the LRR of $\mathrm{L}^{3}$ with the CC-NBS of its paralog $\mathrm{PIH}-\mathrm{X}$, they constructed a functional chimeric protein detecting $\mathrm{P}_{0}$ and $\mathrm{P}_{1}$ variants of the viral coat protein but not $\mathrm{P}_{1,2}$ variants that used to be recognized by full-length $\mathrm{L}^{3}$ (chimera A, Tomita et al. 2011). Interestingly, PIH-X has an extended ARC2 loop sequence as compared with $\mathrm{L}^{3}$. Ashikawa (2012) analyzed the broad-spectrum Pikml-TS gene and the narrowspectrum Pikl-KA gene from the rice blast Pik locus. A chimera with the CC-NBS of Pikm1-TS and the LRR of Pik1-KA kept resistance against a blast isolate that is avirulent on Pikml-TS but virulent on Pikl-KA, demonstrating that one or more of the five polymorphic amino acids in the $\mathrm{CC}$ or of the three polymorphisms in the NBS domain determine the difference in recognition specificity (Ashikawa 2012). All these data for various NBS-LRR resistance proteins show that polymorphisms in the TIR, CC, or NBS domains that are not necessarily involved in the perception of the Avr protein or activity can be important for the outcome of the resistance specificity.

\section{Putative function of the ARC2 loop.}

In this study, we were able to attribute the effect of enhanced resistance activity of multiple PM3 proteins to two amino acid positions in a sequence that was modeled as a loop (Brunner et al. 2010) located C-terminally of the RNBS-D/RNBS-V motif (Meyers et al. 2003; Zhou et al. 2004). This motif is highly conserved, especially in non-TIR-NBS-LRR, but different consensus sequences for the RNBS-D motif are assigned for TIR (EDKDLFLHIACFFNG) and non-TIR (CFLYCALFPED YEIxKEKLIDYWIAEGFI) NBS-LRR proteins (Meyers et al. 2003). This suggests that there is a structural difference between the NBS of TIR and non-TIR proteins, and the identified effect of sequence polymorphisms in the ARC2 loop is possibly relevant only for non-TIR-NBS-LRR. The RNBS-D motif is conserved in neither APAF-1 nor CED-4 (van Ooijen et al. 2008b) and, therefore, is specific for R proteins. For CC-NBS-LRR, multiple gain- (autoactivity) and loss-of-function mutations have been described at the N-terminal end of the RNBS-D motif (Axtell et al. 2001; Bendahmane et al. 2002; Tornero et al. 2002), but the particular mechanistic function, especially of the conserved C-terminal part of the motif that is also part of the ARC2 loop, remains obscure.

Interestingly, loss-of-function mutations have been described for the loop region C-terminal of the RNBS-D motif in the resistance protein RPM1 (P464L, G467R; Tornero et al. 2002). Bearing in mind that the amino acid position does not align perfectly (shift of one position), the P464L substitution in the rpm1-52 mutant allele may correspond to $\mathrm{P} 456 \mathrm{~L}$ that renders PM3 less active. Along with the results for hPM3-1B and Bph14 (Fig. 5A, B, E, and F), these observations demonstrate that the ARC2 loop is an important regulative element of CCNBS-LRR activity. Additionally, they also indicate that a proline-to-leucine substitution in the ARC2 loop dampens or blocks the activity of numerous CC-NBS-LRR.

The best-studied system in regard to the ARC2 loop is the resistance-gene homologues $R x 1$ and Gpa2 (Slootweg et al. 2013). Replacement of 419-EEE in Gpa2 by uncharged amino acids leaves the tested properties of the full-length protein unchanged but disrupts the capability of the CC-NBS fragment to bind its LRR and to be activated by a modified Rx1 LRR in trans (Slootweg et al. 2013). Based on these results in combination with a structural docking model, the authors of the corresponding study predict that the protruding negatively charged loop forms an interface for the interaction with posi- 
tively charged residues at the N-terminal end of the LRR. This electrostatic attraction would be important for reassociation of the receptor after an activation cycle (Slootweg et al. 2013). In PM3, the loop region is also occupied by three acidic amino acids (E457, E459, D460), but the fact that a basic histidine at position 458 is present in strong PM3 proteins evidently stands against the hypothesis that a particular charge is the essential feature of the ARC2 loop for an efficient R protein activity in the PM3 context. The amino acid substitution study at positions 456 and 458 in PM3C (Table 1) also did not indicate that a positive or a negative charge enhances the HR. We were not able to finally elucidate whether an enhanced HR and an expanded recognition specificity caused by $\mathrm{P} 456 / \mathrm{H} 458$ in PM3F correlates with a stronger interaction between the CC-NBS and LRR domains (Fig. 6C).

A PM3-NBS model (Brunner et al. 2010) places the solvent exposed amino acids 456 and 458 at the extremity of the ARC2 subdomain that is not in contact with other parts of the NBS. Whereas amino acids that are directly involved in the binding or hydrolysis of ADP/ATP in the NBS often cause autoactivity when being mutated (van Ooijen et al. 2008b), the central ARC2 loop amino acids are obviously not involved in the formation of the ADP/ATP binding pocket but remain accessible at the NBS surface in models for the ADP-bound as well as the ATP-bound conformation (Brunner et al. 2010; Maekawa et al. 2011; Slootweg et al. 2013; Takken and Goverse 2012; van Ooijen et al. 2008a and b). Consequently, we suspect that NBS interactions either with the CC or the LRR domain, with a guarded host protein, or with downstream signaling components might be modified. We can also not exclude that the enhancing effects of the ARC2 modifications are due to slight changes in the conformation of the NBS itself that make this molecular switch more sensitive to be turned on.

\section{Evolution of the strong ARC2 haplotype.}

The activity-enhancing $P m 3 a / b$-specific ARC2 haplotype has an interesting evolutionary history. It is also found in a PM3-like protein from Aegilops tauschii as well as in PM8, the Pm3 ortholog from rye (Secale cereale), and is conserved in PM3-like proteins from wheat homologous chromosome 1B (hPM3-1B) and barley (Hordeum vulgare). This indicates an ancient origin of this sequence block (Hurni et al. 2013). Interestingly, the presence of the proline-histidine haplotype in the ARC2 loop of hPM3-1B and PM8 also correlates with a fast and intensive HR in the Nicotiana expression system (Fig. 5A and $\mathrm{C}$ ), suggesting conserved functional properties, even in more diverse genes (64\% similarity between hPM3-1B and PM3CS). Pm3CS is the consensus sequence of all isolated Pm3 alleles, was identified in tetraploid wheat accessions (Yahiaoui et al. 2009), and is consequently regarded as the ancestral Pm3 allele in hexaploid wheat (Yahiaoui et al. 2006). It encodes the same CC-NBS domains as the narrow-spectrum allele $\mathrm{Pm} 3 \mathrm{c} / \mathrm{f}$ with its L456/Y458 haplotype, which we only found in Pm3 homologues of tetraploid and hexaploid wheat but not of other related grass species (Wicker et al. 2007a). Thus, the following evolutionary scenario can be proposed. The ancestral gene of $P m 3$ in the Triticeae family possessed an ARC2 sequence block for fast and intensive activity, but by the time that tetraploid wheat was domesticated, the Pm3CS sequence was established as an A-genome copy that was later transmitted to hexaploid bread wheat. After this genetic bottleneck new Pm3 alleles evolved (Yahiaoui et al. 2006) and three of them regained an ARC2 loop for an enhanced resistance signaling, most likely independently through gene conversion $(P m 3 a / b$; Wicker et al. $2007 b)$ or point mutations $(P m 3 s)$. We can only speculate about the evolutionary pressure leading to the interim benefit of the Pm3CS-ARC2, but climatic changes (Alcázar and Parker
2011) and redundant gene function or hybrid necrosis effects (Bomblies and Weigel 2007) after the polyploidization event might have played a role.

\section{ARC2 loop modifications \\ for applied resistance optimization.}

The fact that natural selection led independently at least twice to the reacquisition of $\mathrm{P} 456 / \mathrm{H} 458$ in PM3 since the domestication of wheat highlights the importance of the ARC2 loop and indicates that no negative aspects of possible $\mathrm{Pm} 3$ $L 456 P / Y 458 H$-resistance gene modifications are to be expected. Accordingly the results of this study may have implications for applications. Most obvious is the optimization of narrow-spectrum Pm3 alleles as demonstrated here for Pm3f or the possible (re)activation of $P m 3$ alleles that are so far classified as nonfunctional. Besides a transgenic approach to introduce the modified genes, genome editing technologies based on TALEN (transcription-activator-like-effector nucleases) (Li et al. 2012; Mahfouz et al. 2011) or CRISPR (clustered regularly interspaced short palindromic repeats) (Cong et al. 2013; Mali et al. 2013) hold great promise for such 'minimally invasive,' two-nucleotide resistance enhancement. We think that targeted adaptations or random mutagenesis of the ARC2 loop in other CC-NBS-LRR could also render some of them more effective or extend their resistance spectra. Good candidates for such an approach might be cloned $R$ genes that mediate an intermediate resistance, indicating a residual recognition activity, or $R$ genes that have just recently been overcome. We consider the wheat resistance gene $\mathrm{Sr} 33$, which gives intermediate resistance towards the Ug99 race of stem rust (Periyannan et al. 2013), or the LRR-mutagenized M1 variant of $R x l$, which detects the coat protein of Poplar mosaic virus but does not mediate resistance against the latter (Farnham and Baulcombe 2006), as just two possible target gene options.

It remains to be determined how efficient in terms of resistance-spectrum extension, enhancement of intermediate resistance, or evasion of negative side effects such ARC2 loop modifications in different plant-pathogen systems can be. We consider it possible that additional positive effects, like temperature insensitivity of resistance might be achieved by such approaches of $R$ gene improvement. In summary, the results of this study represent an additional step toward rational design of resistance proteins, and we demonstrate how gene optimization in a model system can be translated into enhanced crop resistance.

\section{MATERIALS AND METHODS}

\section{Construction of plasmid vectors.}

Genes were amplified by polymerase chain reaction from existing plasmids and were cloned into Gateway system compatible entry vectors via Gateway BP Clonase II reactions (Life Technologies, Carlsbad, CA, U.S.A.) or pENTR Directional TOPO Cloning (Life Technologies). Introduction of modifications and cloning of fragments were achieved by Gibson Assembly (NEB, Ipswich, MA, U.S.A.) or by the principle of the QuikChange site-directed mutagenesis kit (Stratagene, La Jolla, CA, U.S.A.). All resulting pENTR plasmids were recombined to the binary vector pIPKb004 (Himmelbach et al. 2007) carrying the double-enhanced Cauliflower mosaic virus $35 S$ promoter by Gateway LR reaction (Life Technologies). Detailed primer and cloning information is available in Supplementary Tables S1 and S2.

\section{Agrobacterium infiltration procedure.}

Binary plasmids were transformed via electroporation into Agrobacterium tumefaciens GV3101 (pMP90) (Koncz and 
Schell 1986). Bacteria were grown overnight in Luria Bertani medium supplemented with appropriate antibiotics, were harvested by centrifugation at $2,500 \times g$ for $15 \mathrm{~min}$, and were resuspended and diluted in infiltration medium $(10 \mathrm{mM}$ morpholineethanesulfonic acid, $\mathrm{pH}$ 5.6, $10 \mathrm{mM} \mathrm{MgCl}_{2}, 150 \mu \mathrm{M}$ acetosyringone) to an optimal density at $600 \mathrm{~nm}=0.8$. After 2 to $4 \mathrm{~h}$ of incubation at room temperature, one or more cultures were mixed in a $1: 1$ or $1: 1: 1$ ratio with an equally treated Agrobacterium p19-silencing-suppressor strain (Voinnet et al. 2003) and were infiltrated with a needleless syringe into the abaxial side of leaves from 4- to 5-week-old Nicotiana benthamiana. Plants were subsequently kept at room temperature in a glasshouse.

\section{Ion leakage measurements.}

Ion leakage was measured with the CM100-2 multiple cell conductivity meter (Reid \& Associates, Johannesburg, South Africa). Two leaf discs ( $7 \mathrm{~mm}$ diameter) were collected from an infiltrated spot at $17 \mathrm{hpi}$ and were transferred separately into $1.5 \mathrm{ml}$ of double distilled $\mathrm{H}_{2} \mathrm{O}$, and conductivity was measured hourly. For better comparability among replicates, all constructs of a Pm3 infiltration set were harvested from the same leaf. Two experiments, each with four individual plants or leaves per set were conducted.

\section{Protein detection.}

Protein detection from four pooled leaf discs ( $5 \mathrm{~mm}$ diameter) per infiltrated area was performed essentially as described by Brunner and associates (2012), except for not having polyvinylpolypyrrolidone (PVPP) in the extraction buffer and using the Chemidoc XRS system (Bio-Rad, Hercules, CA, U.S.A.) for blot development instead of X-ray film. Samples were collected $15 \mathrm{~h}$ after the Agrobacterium infiltration. Protein levels were compared between samples from the same leaf.

\section{Transient resistance assay and leaf segment infection test.}

Wheat seedling leaf infection tests as well as the transient resistance assay with leaves from 7-day-old plants of wheat cultivar Chancellor were performed as described by Brunner and associates (2010). pUbi-GUS reporter plasmid (1.5 $\mu \mathrm{g})$ together with $1.5 \mu \mathrm{g}$ of a tested pIPKb004-Pm3 construct were used per particle bombardment. At least 50 interactions per construct, isolate, and independent experiment were scored. The wheat powdery mildew (B. graminis f. sp. tritici) isolates 96224 and 97028 originate from the former mildew collection of Agroscope, Reckenholz-Tänikon, Switzerland and isolate AK3-11 is from USDA-ARS, North Carolina State University, Raleigh, NC, U.S.A.

\section{Coimmunoprecipitation.}

For coimmunoprecipitation experiments, protein extracts were prepared as described by Sacco and associates (2007) with a few modifications, i.e., $1 \mathrm{~g}$ of coinfiltrated Nicotiana benthamiana leaf material harvested 48 hpi was ground in liquid nitrogen, was resuspended in $3 \mathrm{ml}$ of ice-cold extraction buffer (GTEN [10\% \{vol/vol $\}$ glycerol; $25 \mathrm{mM}$ Tris-HCl, $\mathrm{pH}$ 7.5; $1 \mathrm{mM}$ EDTA; $150 \mathrm{mM} \mathrm{NaCl}], 10 \mathrm{mM}$ dithiothreitol [DTT], 2\% [wt/vol] PVPP, and 1 tablet per $10 \mathrm{ml}$ of complete mini protease inhibitor cocktail [Roche Diagnostics, Mannheim, Germany]) and was cleared by two centrifugation steps at $16,000 \times g$ for $5 \mathrm{~min}$ each at $4^{\circ} \mathrm{C}$. Nonidet P-40 (NP-40) in $100 \mu$ of IP buffer (GTEN, $2 \mathrm{mM}$ DTT, 1 tablet per $20 \mathrm{ml}$ of complete mini protease inhibitor) was added to $1.9 \mathrm{ml}$ of protein extract for a final concentration of $0.15 \%$ (vol/vol). HA epitope-tagged protein was immunoprecipitated with $35 \mu \mathrm{l}$ of anti-HA affinity matrix (Roche Diagnostics) by end-over-end incubation for $1 \mathrm{~h}$ at $4^{\circ} \mathrm{C}$. Agarose beads were washed four times with $1 \mathrm{ml}$ of IP buffer containing $0.15 \%$ (vol/vol) NP-40 and were resuspended in $40 \mu \mathrm{l}$ of $1 \times$ Laemmli buffer (Laemmli 1970). Subsequent protein detection was performed as described above. For detection of myc-tagged proteins, 1:4,000 dilutions of anti-c-myc primary antibodies (rat monoclonal, clone JAC6, sc-56633; Santa Cruz Biotechnology, Santa Cruz, CA, U.S.A.) were used.

\section{Sequence alignments.}

Nucleotide as well as protein sequence alignments were done with CLC Main Workbench version 6.8.4 (CLC Bio, Aarhus, Denmark), using the standard settings.

\section{ACKNOWLEDGMENTS}

We thank D. Peditto for excellent substantial technical support with plasmid clonings, agroinfiltrations, ion leakage assays, and protein work We are grateful to $\mathrm{S}$. Hurni for providing the $P m 8$ plasmids and $h P m 3-1 B$ DNA and to J. Kumlehn for providing the pIPKb004 vector. This work was supported by an Advanced Investigator Grant from the European Research Council (ERC-2009-AdG 249996, Durable resistance) and Swiss National Science Foundation grant 310030B_144081/1. D. Stirnweis, B. Keller, and S. Brunner designed the project. D. Stirnweis designed the experiments, performed protein work, wrote the manuscript, and prepared figures. D. Stirnweis and S. D. Milani performed cloning work, agroinfiltrations, and ion leakage assays. D. Stirnweis, T. Jordan, and S. Brunner performed the transient resistance assay and discussed results. D. Stirnweis, T. Jordan, B. Keller, and S. Brunner revised the manuscript.

\section{NOTE ADDED IN PROOF}

By random mutagenesis, Harris and associates (2013) recently discovered amino acid substitutions in the NB and ARC1 subdomains that enhance the HR and resistance activity of Rx1 in a similar manner as described for PM3 in this study. None of the identified substitution sites in Rx1 match with the polymorphic amino-acid positions in PM3B compared with other PM3 that might explain the strong HR of PM3B_P456L/H458Y.

\section{LITERATURE CITED}

Ade, J., DeYoung, B. J., Golstein, C., and Innes, R. W. 2007. Indirect activation of a plant nucleotide binding site-leucine-rich repeat protein by a bacterial protease. Proc. Natl. Acad. Sci. 104:2531-2536.

Alcázar, R., and Parker, J. E. 2011. The impact of temperature on balancing immune responsiveness and growth in Arabidopsis. Trends Plant Sci. 16:666-675.

Ashikawa, I. 2012. Regions outside the leucine-rich repeat domain determine the distinct resistance specificities of the rice blast resistance genes Pik and Pik-m. Mol. Breeding 30:1531-1535.

Axtell, M. J., McNellis, T. W., Mudgett, M. B., Hsu, C. S., and Staskawicz, B. J. 2001. Mutational analysis of the Arabidopsis RPS2 disease resistance gene and the corresponding Pseudomonas syringae avrRpt2 avirulence gene. Mol. Plant-Microbe Interact. 14:181-188.

Baker, C. J., O`Neill, N. R., Keppler, L. D., and Orlandi, E. W. 1991. Early responses during plant-bacteria interactions in tobacco cell suspensions Phytopathology 81:1504-1507.

Bendahmane, A., Querci, M., Kanyuka, K., and Baulcombe, D. C. 2000. Agrobacterium transient expression system as a tool for the isolation of disease resistance genes: Application to the $R x 2$ locus in potato. Plant J. 21:73-81.

Bendahmane, A., Farnham, G., Moffett, P., and Baulcombe, D. C. 2002. Constitutive gain-of-function mutants in a nucleotide binding site-leucine rich repeat protein encoded at the $R x$ locus of potato. Plant J. 32:195204.

Bernoux, M., Ellis, J. G., and Dodds, P. N. 2011a. New insights in plant immunity signaling activation. Curr. Opin. Plant Biol. 14:512-518.

Bernoux, M., Ve, T., Williams, S., Warren, C., Hatters, D., Valkov, E., Zhang, X., Ellis, J. G., Kobe, B., and Dodds, P. N. 2011b. Structural and functional analysis of a plant resistance protein TIR domain reveals interfaces for self-association, signaling, and autoregulation. Cell Host Microbe 9:200-211.

Bhullar, N. K., Street, K., Mackay, M., Yahiaoui, N., and Keller, B. 2009. Unlocking wheat genetic resources for the molecular identification of previously undescribed functional alleles at the $P m 3$ resistance locus. Proc. Natl. Acad. Sci. 106:9519-9524. 
Bhullar, N. K., Zhang, Z., Wicker, T., and Keller, B. 2010. Wheat gene bank accessions as a source of new alleles of the powdery mildew resistance gene Pm3: A large scale allele mining project. BMC Plant Biol. $10: 88$

Bomblies, K., and Weigel, D. 2007. Hybrid necrosis: Autoimmunity as a potential gene-flow barrier in plant species. Nat. Rev. Genet. 8:382-393.

Brunner, S., Hurni, S., Streckeisen, P., Mayr, G., Albrecht, M., Yahiaoui, N., and Keller, B. 2010. Intragenic allele pyramiding combines different specificities of wheat Pm3 resistance alleles. Plant J. 64:433-445.

Brunner, S., Stirnweis, D., Diaz Quijano, C., Buesing, G., Herren, G., Parlange, F., Barret, P., Tassy, C., Sautter, C., Winzeler, M., and Keller, B. 2012. Transgenic Pm3 multilines of wheat show increased powdery mildew resistance in the field. Plant Biotechnol. J. 10:398-409.

Chang, C., Yu, D., Jiao, J., Jing, S., Schulze-Lefert, P., and Shen, Q.-H 2013. Barley MLA immune receptors directly interfere with antagonistically acting transcription factors to initiate disease resistance signaling. Plant Cell 25:1158-1173.

Cong, L., Ran, F. A., Cox, D., Lin, S., Barretto, R., Habib, N., Hsu, P. D., Wu, X., Jiang, W., Marraffini, L. A., and Zhang, F. 2013. Multiplex genome engineering using CRISPR/Cas systems. Science 339:819-823.

Dodds, P. N., and Rathjen, J. P. 2010. Plant immunity: Towards an integrated view of plant-pathogen interactions. Nat. Rev. Genet. 11:539548.

Dodds, P. N., Lawrence, G. J., Catanzariti, A.-M., Teh, T., Wang, C.-I. A., Ayliffe, M. A., Kobe, B., and Ellis, J. G. 2006. Direct protein interaction underlies gene-for-gene specificity and coevolution of the flax resistance genes and flax rust avirulence genes. Proc. Natl. Acad. Sci. U.S.A. 103:8888-8893.

Du, B., Zhang, W., Liu, B., Hu, J., Wei, Z., Shi, Z., He, R., Zhu, L., Chen, R., Han, B., and He, G. 2009. Identification and characterization of Bph14, a gene conferring resistance to brown planthopper in rice. Proc. Natl. Acad. Sci. U.S.A. 106:22163-22168.

Ellis, J. G., Lawrence, G. J., Luck, J. E., and Dodds, P. N. 1999. Identification of regions in alleles of the flax rust resistance gene $L$ that determine differences in gene-for-gene specificity. Plant Cell 11:495-506.

Farnham, G., and Baulcombe, D. C. 2006. Artificial evolution extends the spectrum of viruses that are targeted by a disease-resistance gene from potato. Proc. Natl. Acad. Sci. U.S.A. 103:18828-18833.

Gao, Z., Chung, E.-H., Eitas, T. K., and Dangl, J. L. 2011. Plant intracellular innate immune receptor Resistance to Pseudomonas syringae $p v$. maculicola 1 (RPM1) is activated at, and functions on, the plasma membrane. Proc. Natl. Acad. Sci. U.S.A. 108:7619-7624.

Harris, C. J., Slootweg, E. J., Goverse, A., and Baulcombe, D. C. 2013. Stepwise artificial evolution of a plant disease resistance gene. Proc. Natl. Acad. Sci. U.S.A. 110:21189-21194.

Himmelbach, A., Zierold, U., Hensel, G., Riechen, J., Douchkov, D., Schweizer, P., and Kumlehn, J. 2007. A set of modular binary vectors for transformation of cereals. Plant Physiol. 145:1192-1200.

Houterman, P. M., Ma, L., van Ooijen, G., de Vroomen, M. J., Cornelissen, B. J. C., Takken, F. L. W., and Rep, M. 2009. The effector protein Avr2 of the xylem-colonizing fungus Fusarium oxysporum activates the tomato resistance protein I-2 intracellularly. Plant J. 58:970-978.

Hurni, S., Brunner, S., Buchmann, G., Herren, G., Jordan, T., Krukowski, P., Wicker, T., Yahiaoui, N., Mago, R., and Keller, B. 2013. Rye Pms and wheat Pm3 are orthologous genes and show evolutionary conservation of resistance function against powdery mildew. Plant J. doi 10.1111/tpj.12345. Published online.

Jones, J. D. G., and Dangl, J. L. 2006. The plant immune system. Nature 444:323-329

Koncz, C., and Schell, J. 1986. The promoter of TL-DNA gene 5 controls the tissue-specific expression of chimaeric genes carried by a novel type of Agrobacterium binary vector. Molec. Gen. Genet. 204:383-396.

Krasileva, K. V., Dahlbeck, D., and Staskawicz, B. J. 2010. Activation of an Arabidopsis resistance protein is specified by the in planta association of its leucine-rich repeat domain with the cognate oomycete effector. Plant Cell 22:2444-2458.

Laemmli, U. K. 1970. Cleavage of structural proteins during the assembly of the head of bacteriophage T4. Nature 227:680-685

Li, T., Liu, B., Spalding, M. H., Weeks, D. P., and Yang, B. 2012. Highefficiency TALEN-based gene editing produces disease-resistant rice. Nat. Biotech. 30:390-392.

Luck, J. E., Lawrence, G. J., Dodds, P. N., Shepherd, K. W., and Ellis, J. G. 2000. Regions outside of the leucine-rich repeats of flax rust resistance proteins play a role in specificity determination. Plant Cell 12:1367-1378.

Ma, L., Lukasik, E., Gawehns, F., and Takken, F. L. W. 2012. The use of agroinfiltration for transient expression of plant resistance and fungal effector proteins in Nicotiana benthamiana leaves. Pages 61-74 in: Plant Fungal Pathogens, Methods in Molecular Biology. M. D. Bolton and B. P. H. J. Thomma, eds. Humana Press, Totowa, NJ, U.S.A.
Mackey, D., Holt, B. F., III, Wiig, A., and Dangl, J. L. 2002. RIN4 interacts with Pseudomonas syringae type III effector molecules and is required for RPM1-mediated resistance in Arabidopsis. Cell 108:743754.

Maekawa, T., Cheng, W., Spiridon, L. N., Töller, A., Lukasik, E., Saijo, Y., Liu, P., Shen, Q.-H., Micluta, M. A., Somssich, I. E., Takken, F. L. W. Petrescu, A.-J., Chai, J., and Schulze-Lefert, P. 2011. Coiled-coil domaindependent homodimerization of intracellular barley immune receptors defines a minimal functional module for triggering cell death. Cell Host Microbe 9:187-199.

Mahfouz, M. M., Li, L., Shamimuzzaman, M., Wibowo, A., Fang, X. and Zhu, J.-K. 2011. De novo-engineered transcription activator-like effector (TALE) hybrid nuclease with novel DNA binding specificity creates double-strand breaks. Proc. Natl. Acad. Sci. U.S.A. 108:26232628.

Mali, P., Yang, L., Esvelt, K. M., Aach, J., Guell, M., DiCarlo, J. E., Norville, J. E., and Church, G. M. 2013. RNA-Guided Human Genome Engineering via Cas9. Science 339:823-826.

Marone, D., Russo, M., Laidò, G., De Leonardis, A., and Mastrangelo, A. 2013. Plant nucleotide binding site-leucine-rich repeat (NBS-LRR) genes: Active guardians in host defense responses. Int. J. Mol. Sci. 14:7302-7326.

Meyers, B. C., Kozik, A., Griego, A., Kuang, H., and Michelmore, R. W. 2003. Genome-wide analysis of NBS-LRR-encoding genes in Arabidopsis. Plant Cell 15:809-834.

Moffett, P., Farnham, G., Peart, J., and Baulcombe, D. C. 2002. Interaction between domains of a plant NBS-LRR protein in disease resistance-related cell death. EMBO (Eur. Mol. Biol. Organ.) J. 21:45114519 .

Padmanabhan, M., Cournoyer, P., and Dinesh-Kumar, S. P. 2009. The leucine-rich repeat domain in plant innate immunity: A wealth of possibilities. Cell. Microbiol. 11:191-198.

Periyannan, S., Moore, J., Ayliffe, M., Bansal, U., Wang, X., Huang, L., Deal, K., Luo, M., Kong, X., Bariana, H., Mago, R., McIntosh, R., Dodds, P., Dvorak, J., and Lagudah, E. 2013. The gene Sr33, an ortholog of barley Mla genes, encodes resistance to wheat stem rust race $\mathrm{Ug} 99$. Science 341:786-788

Rafiqi, M., Bernoux, M., Ellis, J. G., and Dodds, P. N. 2009. In the trenches of plant pathogen recognition: Role of NB-LRR proteins. Semin. Cell Dev. Biol. 20:1017-1024.

Sacco, M. A., Mansoor, S., and Moffett, P. 2007. A RanGAP protein physically interacts with the NB-LRR protein $\mathrm{Rx}$, and is required for Rxmediated viral resistance. Plant J. 52:82-93.

Schweizer, P., Pokorny, J., Abderhalden, O., and Dudler, R. 1999. A transient assay system for the functional assessment of defense-related genes in wheat. Mol. Plant-Microbe Interact. 12:647-654.

Shen, Q.-H., Saijo, Y., Mauch, S., Biskup, C., Bieri, S., Keller, B., Seki, H., Ulker, B., Somssich, I. E., and Schulze-Lefert, P. 2007. Nuclear activity of MLA immune receptors links isolate-specific and basal disease-resistance responses. Science 315:1098-1103.

Slootweg, E. J., Spiridon, L. N., Roosien, J., Butterbach, P., Pomp, R., Westerhof, L., Wilbers, R., Bakker, E., Bakker, J., Petrescu, A.-J., Smant, G., and Goverse, A. 2013. Structural determinants at the interface of the ARC2 and leucine-rich repeat domains control the activation of the plant immune receptors Rx1 and Gpa2. Plant Physiol. 162:15101528

Takken, F. L., and Goverse, A. 2012. How to build a pathogen detector: Structural basis of NB-LRR function. Curr. Opin. Plant Biol. 15:375384.

Takken, F. L., Albrecht, M., and Tameling, W. I. 2006. Resistance proteins: Molecular switches of plant defence. Curr. Opin. Plant Biol. 9:383-390.

Tameling, W. I. L., and Baulcombe, D. C. 2007. Physical association of the NB-LRR resistance protein Rx with a Ran GTPase-activating protein is required for extreme resistance to Potato virus $X$. Plant Cell 19:1682-1694.

Tameling, W. I. L., Vossen, J. H., Albrecht, M., Lengauer, T., Berden, J. A., Haring, M. A., Cornelissen, B. J. C., and Takken, F. L. W. 2006. Mutations in the NB-ARC domain of I-2 that impair ATP hydrolysis cause autoactivation. Plant Physiol. 140:1233-1245.

Tang, X., Frederick, R. D., Zhou, J., Halterman, D. A., Jia, Y., and Martin, G. B. 1996. Initiation of plant disease resistance by physical interaction of AvrPto and Pto kinase. Science 274:2060-2063.

Tomita, R., Sekine, K.-T., Mizumoto, H., Sakamoto, M., Murai, J., Kiba, A., Hikichi, Y., Suzuki, K., and Kobayashi, K. 2011. Genetic basis for the hierarchical interaction between Tobamovirus spp. and $L$ resistance gene alleles from different pepper species. Mol. Plant-Microbe Interact. 24:108-117.

Tornero, P., Chao, R. A., Luthin, W. N., Goff, S. A., and Dangl, J. L. 2002. Large-scale structure-function analysis of the Arabidopsis RPM1 disease resistance protein. Plant Cell 14:435-450. 
Van den Ackerveken, G., Marois, E., and Bonas, U. 1996. Recognition of the bacterial avirulence protein AvrBs3 occurs inside the host plant cell. Cell 87:1307-1316.

Van der Hoorn, R. A. L., Laurent, F., Roth, R., and De Wit, P. J. G. M. 2000. Agroinfiltration is a versatile tool that facilitates comparative analyses of $A v r 9 / C f$-9-induced and $A v r 4 / C f$-4-induced necrosis. Mol Plant-Microbe Interact. 13:439-446.

Van Ooijen, G., Mayr, G., Albrecht, M., Cornelissen, B. J. C., and Takken, F. L. W. 2008a. Transcomplementation, but not physical association of the CC-NB-ARC and LRR domains of tomato R protein Mi-1.2 is altered by mutations in the ARC2 subdomain. Mol. Plant 1:401-410.

Van Ooijen, G., Mayr, G., Kasiem, M. M. A., Albrecht, M., Cornelissen, B. J. C., and Takken, F. L. W. 2008b. Structure-function analysis of the NB-ARC domain of plant disease resistance proteins. J. Exp. Bot. 59:1383-1397.

Voinnet, O., Rivas, S., Mestre, P., and Baulcombe, D. 2003. An enhanced transient expression system in plants based on suppression of gene silencing by the p19 protein of Tomato bushy stunt virus. Plant J. 33:949-956.

Wicker, T., Yahiaoui, N., and Keller, B. 2007a. Contrasting rates of evolu- tion in Pm3 loci from three wheat species and rice. Genetics 177:12071216

Wicker, T., Yahiaoui, N., and Keller, B. 2007b. Illegitimate recombination is a major evolutionary mechanism for initiating size variation in plant resistance genes. Plant J. 51:631-641.

Williams, S. J., Sornaraj, P., deCourcy-Ireland, E., Menz, R. I., Kobe, B., Ellis, J. G., Dodds, P. N., and Anderson, P. A. 2011. An autoactive mutant of the $\mathrm{M}$ flax rust resistance protein has a preference for binding ATP, whereas wild-type M protein binds ADP. Mol. Plant-Microbe Interact. 24:897-906.

Yahiaoui, N., Brunner, S., and Keller, B. 2006. Rapid generation of new powdery mildew resistance genes after wheat domestication. Plant $\mathrm{J}$. 47:85-98.

Yahiaoui, N., Kaur, N., and Keller, B. 2009. Independent evolution of functional Pm3 resistance genes in wild tetraploid wheat and domesticated bread wheat. Plant J. 57:846-856.

Zhou, T., Wang, Y., Chen, J.-Q., Araki, H., Jing, Z., Jiang, K., Shen, J., and Tian, D. 2004. Genome-wide identification of NBS genes in japonica rice reveals significant expansion of divergent non-TIR NBS-LRR genes. Mol. Genet. Genomics. 271:402-415. 